\title{
ANAESTHESIA FOR DWARFS AND OTHER PATIENTS OF PATHOLOGICAL SMALL STATURE
}

\author{
Leonard F. Walts, M.d., "Gerald Finerman, M.D., † and \\ GREGORY M. WYATT, M.D.
}

\section{INTRODUCTION}

INTEREST in the selection and management of anaesthesia for the dwarf and other patients of short stature was generated by the necessity of one of the authors (LFW) to anaesthetize a child with spondyloephiphyseal dysplasia. The patient's mother was apprehensive about anaesthesia since she had been told six years earlier that the dwarfed patient tolerated anaesthesia poorly. At that time the proposed operation, a myringotomy, had not been performed when, according to the mother, the anaesthesiologist refused to administer anaesthesia.

Since the child was now scheduled for a necessary orthopaedic operation, a search of the literature was undertaken to determine the anaesthetic problems encountered in patients of short stature. The search, which included current literature and standard anaesthesia texts, was unproductive. The only recently published anaesthesia book that contained a reference to the dwarf limited the discussion to two paragraphs and made no mention of anaesthesia. ${ }^{1}$

The void in the anaesthesia literature prompted us to report this case and to review our past experience in administering anaesthetics to these patients.

\section{CASE Report}

The patient was a fourteen-year-old female who entered the hospital with a diagnosis of an unusual form of spondyloepiphyseal dysplasia. Because of chronic pain and increasing difficulty with locomotion, the surgeon planned to relocate the patellar mechanism of her left knee. She was born to a 30-year-old healthy woman following a full term pregnancy and normal labor. Physical development was severely delayed; the patient did not sit until 16 months of age and did not walk until four years of age. Her mental development was entirely normal. On physical examination, the patient weighed $21 \mathrm{~kg}$ (average for 5-6 years old) and stood 82 $\mathrm{cm}$ tall (average for 19 months old). Her head was elongated with rhyzomelic shortening and her neck was short. She had marked thoracic kyphosis and lumbar lordosis. Additionally, she suffered from bilateral dislocated hips. The patient had full range of motion of the temporal-mandibular joints and was able to extend her neck. Cervical X-rays revealed odontoid dysplasia (Figure 1). Laboratory findings were normal. No mucopolysaccharides were found in her urine.

From the Department of Anaesthesiology ${ }^{\circ}$ and Division of Orthopedic Surgery $f_{\text {U.C.L.A., }}$ School of Medicine, Los Angeles, California 90024, U.S.A. 


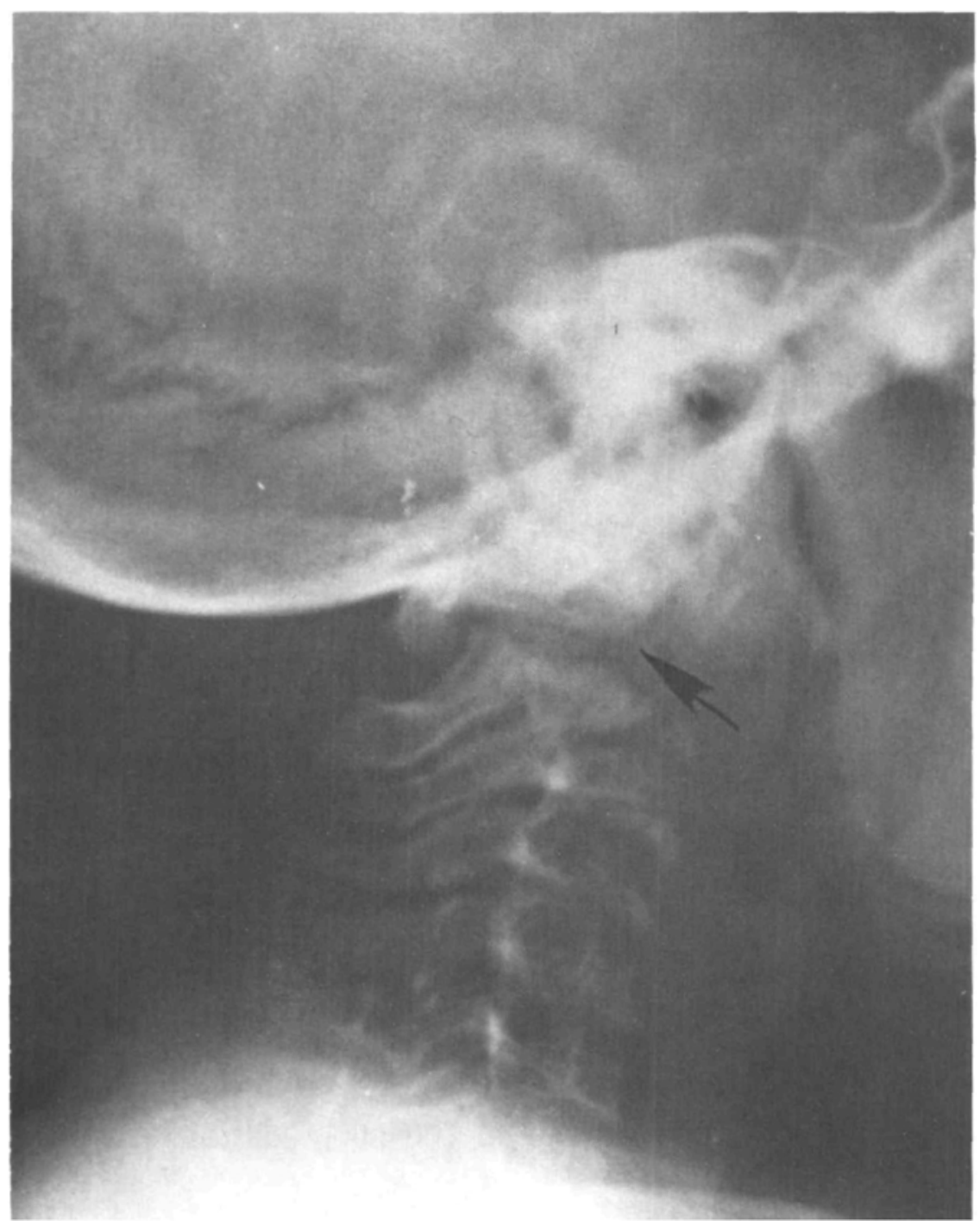

Frgune 1. The arrow points to the dysplastic odontoid process of the second cervical vertebrae.

The patient was given morphine sulfate $4 \mathrm{mg}$ and diazepam $5 \mathrm{mg}$ for premedication approximately 75 minutes prior to anaesthesia induction. Anaesthesia was induced by mask using nitrous oxide, oxygen, and halothane. After the patient lost consciousness, an intravenous infusion of 5 per cent dextrose in lactated Ringer's solution was begun. Succinylcholine $40 \mathrm{mg}$ was injected to facilitate tracheal intubation. The vocal cords were easily visualized and a $6.5 \mathrm{~mm}$ tube was inserted without difficulty. Moments after the tube was placed the ECG revealed a ventricular bigeminal pattern. On auscultation of the chest breath sounds were found to be absent on the left. The tube was withdrawn $2 \mathrm{~cm}$, allowing bilateral pulmonary ventilation. The arrhythmia reverted to normal sinus rhythm within one 
minute. During the 80 -minute operation vital signs remained stable. The patient was reactive when leaving the operating room and awake prior to discharge from the recovery room. Her post-anaesthetic course was uneventful.

\section{Review of Past Experience}

A ten-year search of our medical records revealed that 29 patients diagnosed as dwarfs or having pathologically short stature had been given a total of 69 anaesthetics. We have divided these patients into three categories according to the nature of their disease. Group 1 included 11 achondroplastic dwarfs; Group 2 included eight patients with disproportionate small stature who had diagnoses other than achondroplasia; Group 3 included ten patients who had proportionate small stature.

\section{DWARF-AChondroplasia}

The 11 patients in Group 1 were given a total of 24 anaesthetics. Slightly less than one-third of the operations were on the musculoskeletal system. An additional one-fourth of the operations were obstetrical or gynaecological (Table I). Four of the patients were in the paediatric age group. Tracheal tubes were placed in three of these children (Table II). Eighteen of the procedures were performed with general anaesthesia and six with conduction anaesthesia. The most commonly used anaesthetic agents were nitrous oxide, oxygen, and halothane (Table III).

There were no serious complications associated with any of the anaesthetic agents or techniques. One patient became hypotensive after spinal anaesthesia for Caesarean section. Attempted spinal anaesthesia was abandoned in another patient because of the inability to perform a lumbar puncture. A planned epidural anaesthesia in the same patient was converted to spinal anaesthesia due to an inadvertent lumbar puncture. Since this patient had been given uncomplicated spinal and epidural anaesthesia on other occasions the failures were attributed to faulty technique. A note found on the chart of a third patient indicated that tracheal intubation was performed with moderate difficulty due to inability to extend the neck.

\section{Duarfs - other than achondroplasia}

These eight patients had diagnoses of (1) spondyloepiphyseal dysplasia (see case report), (2) Schwartz-Jampel Osteochondrodystrophy, (3) metaphyseal

TABLE I

NATURE OF OpERATIONS

\begin{tabular}{lccccccc}
\hline \hline & $\begin{array}{c}\text { Musculo- } \\
\text { skeletal }\end{array}$ & Urologic & $\begin{array}{c}\text { Ob } \\
\text { gyn }\end{array}$ & CNS & Cardiac & $\begin{array}{c}\text { Minor } \\
\text { plastic }\end{array}$ & Other \\
\hline $\begin{array}{l}\text { Dwarf } \\
\text { achondroplasia }\end{array}$ & 7 & 5 & 6 & 1 & 0 & 0 & 5 \\
$\begin{array}{l}\text { Owarf } \\
\text { Pther }\end{array}$ & 6 & 6 & 2 & 0 & 0 & 1 & 4 \\
$\quad \begin{array}{l}\text { stoportionate } \\
\text { small stature }\end{array}$ & 0 & 9 & 0 & 5 & 4 & 5 & 3 \\
\hline
\end{tabular}



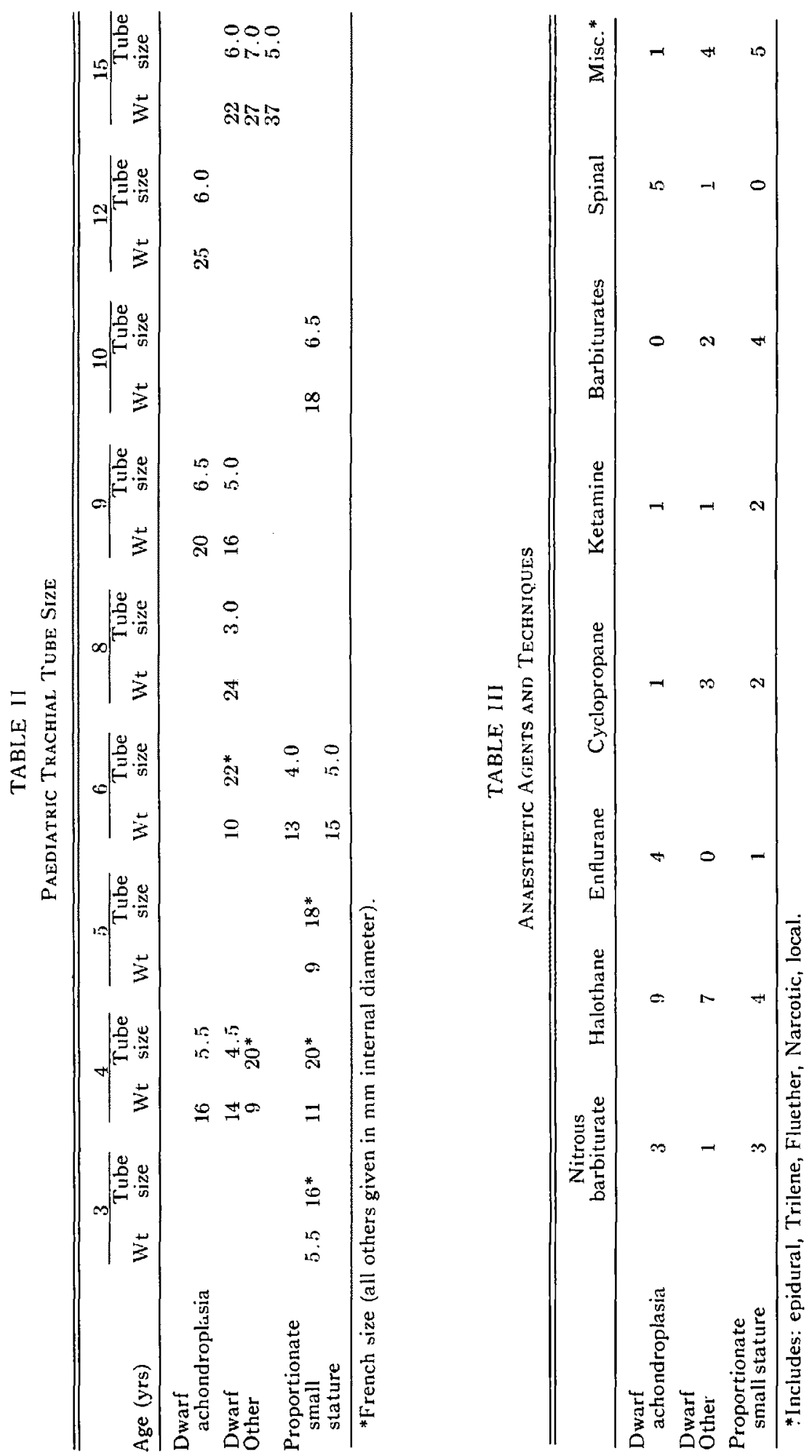
chondrodysplasia type McKusick (cartilage-hair hypoplasia) and (4) dwarf of undertimed aetiology. These patients were anaesthetized a total of 19 times. Slightly less than one-third of the operations were related to musculoskeletal deformities. Urological procedures made up another one-third of the operations (Table I). All but one of the anaesthetics were given to paediatric age patients. The exception was a 27 -year-old woman having a Caesarean section. Tracheal tubes were inserted eight times (Table II). The most common anaesthetic agents used were nitrous oxide, oxygen, and halothane (Table III). Problems related to anaesthesia were few and minor. One patient had a cardiac arrhythmia following tracheal intubation ( see case report). Due to an anterior larynx in another patient, the anaesthetist was unable to insert a tracheal tube on one occasion and noted that the tube was placed with difficulty on a second occasion. The single adult was given spinal anaesthesia. A note on the record indicated that the lumbar puncture was performed with difficulty and the patient became hypotensive following the block.

\section{Patients with proportionate small stature}

The ten patients in this group were anaesthetized a total of 26 times. The most common operations were those involving the genitourinary system. In addition, anaesthesia was common for central nervous system diagnostic procedures, minor plastic operations, and diagnostic or definitive cardiac operations. No operation was performed for musculoskeletal deformities (Table I). Twenty-one anaesthetics were given to patients in the paediatric age range. Tracheal tubes were placed in six of these patients (Table II). Multiple general anaesthetic agents were used (Table III). The problems related to anaesthesia were: (1) Inability to place an endotracheal tube in a patient with an associated Treacher-Collins syndrome; (2) cardiac arrhythmia during cardiac catheterization carried out under barbiturate anaesthesia; (3) brief apnoea following Innovar ${ }^{\circledR}$ given to facilitate a radiological procedure; (4) moderate temperature elevation during repair of pulmonary stenosis.

\section{Comment}

In our series of eight achondroplastic dwarfs subarachnoid and epidural anaesthesia were used six times. The operations for which these anaesthetic techniques were chosen included Caesarean section, herniorrhaphy, and osteotomy of the femur. There were several instances of technical difficulty in performing the blocks; however, no neurological complications developed after the anaesthesia. Despite our finding no post-anaesthetic neurological problems in this small series, the choice of conduction anaesthesia for the achondroplastic dwarf may not be wise. Nelson has reported that achondroplastic dwarfs often develop neurological problems in the third and fourth decade of life." These problems result from a disproportion between the neural contents and the spinal canal space. In addition, achondroplastic dwarfs are prone to disc disease, severe thoraco-lumbar kyphosis, and foramen magnum insufficiency, conditions which may result in hemi or quadraparesis. In view of the recognized neurological problems associated with achondroplasia it would be prudent to consider inhalation techniques when anaesthetizing these patients. Spinal anaesthesia should be reserved for the patients in 
whom there is a specific indication and in whom the immediate advantages of conduction anaesthesia outweigh other considerations.

Dwarfs of non-achondroplastic type often have an associated odontoid dysplasia. When this abnormality is accompanied by atlanto-axial instability patients are in danger of cervical cord compression. We are aware of two patients who developed cord compression during anaesthesia, one becoming quadraparetic and the other hemiparetic.

In an X-ray study evaluating the spinal cord of dwarfs Perovic, et al. found that 75 per cent of non-achondroplastic dwarfs had atlanto-axial instability and more than 50 per cent of these patients had myelopathy. ${ }^{3}$ When one considers the high risk of cord compression in patients with these congenital defects, it would seem advisable to obtain X-rays of the cervical spine in any dwarf who has had a history of neurological symptoms. Should the patient be found to have a dysplastic odontoid process, precautions must be taken to avoid neck flexion. Application of cervical stabilizing devices such as a halo cast or a plaster bed ${ }^{4}$ should be considered.

The patient described in this case report had X-ray evidence of odontoid dysplasia and an associated atlanto-axial instability. Because of the potential hazard of neck flexion, her head was kept hyperextended throughout the course of anaesthesia. No neurological changes developed during the anaesthetic nor in the postoperative period.

In preparing the study we expected to be able to make some generalizations about the choice of tracheal tube size for small children and dwarfs. We anticipated that the patient's weight would be the best guide to tube size in the child who was proportionately small and that age would be the best guide in the dwarf. Presumably, the dwarf has a normal torso size and tracheal diameter. Using the guidelines suggested by Smith ${ }^{5}$ and Cullen and Larson ${ }^{6}$ we found that weight was generally a better predictor of tube size in children with proportionate small stature (Table II). Our experience with achondroplastic dwarfs was too meager to draw any conclusion. In the group of dwarfs other than achondroplasia, neither age nor weight seemed to be the ideal predictor of tracheal tube size. Generally the size selected was smaller than would be suggested using either of these criteria. However, since this is a retrospective study it is not possible to know whether the tube actually used was of optimal fit.

\section{CONClusion AND SUMmary}

Sixty-nine anaesthetics were administered to 29 patients of pathological proportionate and disproportionate small stature. The anaesthetic course in most cases was uncomplicated. The few complications noted were similar in type and severity to those found in normal size patients undergoing similar anaesthesia and operative procedures. Achondroplastic dwarfs often develop neurological problems due to their bony deformities. General anaesthesia should be given preferential consideration in these patients. Non-achondroplastic dwarfs may have an associated odontoid dysplasia and if the neck is placed in flexion there is a potential risk of spinal cord damage. Tube size for proportionately small children is best estimated from 
body weight. No definite recommendations concerning proper tube size in dwarfs can be given on the basis of the findings in this study.

\section{RÉSUMÉ}

Un enfant de 14 ans, présentant un nanisme congénital du type dysplasie spondylo-épiphysaire, a reçu une anesthésie générale à l'occasion d'une reposition de la rotule. Le maintien et l'anesthésie fut faits à l'aide du Protoxyde d'Azote, d'Oxygène et d'Halotane. L'enfant a présenté de l'arythmie ventriculaire causée par une intubation dans la bronche-souche droite. Le tube fut retiré et l'intervention s'est poursuivie sans incident.

A loccasion de cette intervention, nous avons relevé les dossiers d'anesthésie de 29 patients présentant un nanisme avec proportions normales ou anormales. Ces malades ont été anesthésies à 69 reprises avec des agents et des techniques variés. Ils n'ont présenté que des problèmes d'ordre mineur, à savoir de l'arythmie occasionnelle, des épisodes d'hypotension et des problèmes d'intubation.

Les nains du type achondro-plastique présentent fréquemment des complications neurologiques, suite à leurs malformations osseuses. Pour cette raison, il est recommandé d'utiliser chez eux une anesthésie générale.

Ceux qui présentent une dysplasie odontoïde et une instabilité de l'articulation atlas-axis peuvent subir un traumatisme médullaire si leurs vertèbres sont fléchies et pour cette raison on doit porter beaucoup d'attention lors du positionnement de ces malades.

Il est préférable de choisir le calibre du tube endotrachéal en fonction du poids plutôt qu'en fonction de l'âge; notre série était cependant trop petite pour nous permettre de l'établir.

\section{REFERENCES}

1. Zackheim, H.S., Rudzinski, D.J., Katz, J., \& Spademan, G. Skin and bone disorders, in Katz, J. and Kadis, L.B. (ed.). Anesthesia and Uncommon Diseases, 1st ed., Philadelphia: Saunders (1973).

2. Nelson, M.A. Spinal stenosis in achondroplasia. Proc. Roy. Soc. Med. 65: 18 (1972).

3. Perovic, M.N., Kopits, S.E., \& Thompson, R.C. Radiological evaluation of the spinal cord in congenital atlanto-axial dislocation. Radiology 109: 713 (1973).

4. Birkinsiraw, K.J. Anaesthesia in a patient with an unstable neck. Anaesthesia 30: 46 (1975).

5. Smrrh, R.M. Anesthesia for infants and children, 3rd ed. St. Louis: C.V. Mosby Co. (1973).

6. Cullen, S.C. \& Larson, C.P. Essentials of anesthetic practice, lst ed. Chicago: Year Book Medical Publishers (1974). 